Farm animal welfare - who writes the rules?

Occasional Publication No. 23 - British Society of Animal Science 1999

edited by A. J. F. Russel, C. A. Morgan, C. J. Savory, M. C. Appleby and T. L. J. Lawrence

\title{
The specification of stocking density in relation to the welfare of finishing pigs
}

\author{
H. A. M. Spoolder ${ }^{1}$, S. Corning ${ }^{1}$ and S. A. Edwards ${ }^{2}$ \\ ${ }^{1}$ ADAS Terrington, Terrington St Clement, King's Lynn PE34 4PW \\ ${ }^{2}$ Scottish Agricultural College, Craibstone Estate, Bucksburn, Aberdeen AB2 $9 Y$ A
}

\section{Introduction}

The Welfare of Livestock Regulations (Great Britain Parliament, 1994) specify a system of increasing space allowance for finishing pigs based on a series of weight bands (Figure 1). However, the width of the bands in the Regulations impose a great degree of inflexibility on the management of finishing pig accommodation. By law, a producer with fully slatted flatdeck facilities designed to house second stage weaners from 17 to $35 \mathrm{~kg}$ live weight, would have to house pigs at $0.4 \mathrm{~m}^{2}$ per pig. A $2 \times 4 \mathrm{~m}$ pen would therefore house 20 animals.

An alternative approach to specifying space allowance is to use the equation suggested by Edwards et al. (1988), which continuously relates total space requirements (A) to average pig live weight $\mathrm{M}: \mathrm{A}\left(\mathrm{m}^{2}\right)=0.030 \times \mathrm{M}^{0.67}(\mathrm{~kg})$ (see Figure 1). Using this equation in the above example, a producer would need to allow $0.32 \mathrm{~m}^{2}$ per $35 \mathrm{~kg}$ pig and be able to house 24 pigs in the same pen. However, before the use of this equation can be considered, its welfare advantages and disadvantages relative to existing legislation will have to be investigated in a worst-case scenario: a hypothetical one in which a producer would offer the minimum level of space per pig based on either the equation or the banded system.

The type of flooring (solid or slatted) and the presence of bedding may well affect the outcome of any stocking density experiment. Both the space

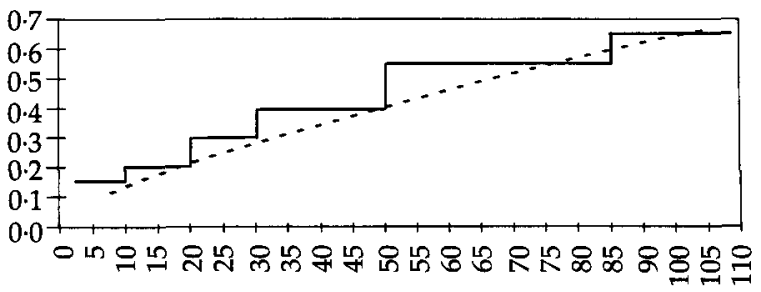

Figure 1 The relationship between stocking density and average weight of pigs per pen according to the equation $\mathrm{A}\left(\mathrm{m}^{2}\right)=0.030 \times \mathrm{M}^{0.67}(\mathrm{~kg})(-\quad-\quad)$ and according to the Welfare of Livestock Regulations 1994 (- $)$. allowance methods described above, ignore the quality of the floor and only relate pig weight to 'total unobstructed floor area'. Previous recommendations in the 1983 Welfare Codes specified a precise lying area but did not indicate the amount of extra space needed for other functions.

The present study therefore looked at the effects on pig welfare of providing space at the minimum stocking densities described by the bands of the Regulations, compared with those calculated using the equation by Edwards et al. (1988), in fully slatted accommodation as well as on solid floors with and without straw.

\section{Material and methods}

Eighteen groups of 12 pigs (weight 29.1 (s.d. 4.2) kg) were allocated to a $2 \times 3$ factorial experiment. It compared space allowance, increasing according to the above equation (E) or to the banded system (B) and floor type: fully slatted $(\mathrm{F})$, solid sloping floor without straw $(\mathrm{N})$ or solid sloping floor with straw bedding (S). Each of the six treatments had three replicate pens, giving a total of 18 pens (216 animals). Groups remained on treatment until an average weight of $110 \mathrm{~kg}$ was reached. Concentrate food and water were provided ad libitum. Straw was available to animals on the $S$ treatments from a straw hopper, which was topped up daily.

All pigs were weighed every fortnight. E pens were adjusted to a size determined by the anticipated average weight of the pigs a week from the date of weighing, using the equation. B pens were adjusted on the day the predicted average weight of the pigs reached the next band (i.e. at $50 \mathrm{~kg}$ or at $85 \mathrm{~kg}$ ). Floor area of the pen was increased whilst maintaining the same ratio between length and width of the pen.

Data were collected on a wide range of parameters, such as performance (weight gain, food intake), behaviour (time budgets, skin damage), pen cleanliness post-slaughter pathology (stomach lesions, heart lesions, weight of adrenal glands) and health records. 


\section{Results}

Performance

The only significant effect of stocking density treatment was found on the hot weight at slaughter $(78.4 v .81 .1 \mathrm{~kg}$ for B $v$. E respectively; $P<0.05)$, although related variables (such as sale weight and killing-out proportion) were not different. There was a tendency for backfat levels to be lower at slaughter in F pigs compared with $\mathrm{N}$ pigs $(9.53 v .10 .17 \mathrm{~mm}$, for F v. N respectively; $P<0 \cdot 1$ ). Daily live-weight gain was not affected by any of the treatments.

\section{Behaviour}

A total of 10250 lines of data were collected with information on the behaviour, substrate used and posture of 72 focal pigs (two males and two females in each of the 18 pens). No effects at all of the stocking density treatment were found on any of the behavioural parameters measured. Manipulation of pen components (straw, floor, walls, etc.) was lowest in $N$ pigs $(52,47$ and $57 \%$ of active time for $F, N$ and $S$ respectively; $P<0.05$ ), of which in $S$ pigs about $45 \%$ of active time was spent manipulating straw. There was an indication that oral behaviours (tongue sucking, sham chewing) occurred more frequently in $\mathrm{F}$ than in $\mathrm{N}$ pens $(1.5 v .0 .4 \%, \mathrm{~F} v . \mathrm{N} ; P<0.1)$, but pen mate manipulation did not differ. The average skin lesions scores were not different between the stocking density treatments but a smaller number of lesions were found on pigs of the non-straw treatment $(8.5,4.8$ and 8.3 lesions on average for $\mathrm{F}, \mathrm{N}$ and $\mathrm{S}$ respectively; $P<0.05$ ). However, this may have been confounded by pen cleanliness.

\section{Cleanliness}

Strawed pens had a smaller proportion of the floor area soiled than pens with barren floors $(58.8 \mathrm{v}$. $76.5 \%$ clean floor area for without straw and with straw respectively; $P<0.001$ ). There was no relationship between the proportion of pen area soiled and the stocking density treatment (68.7 $v$. $66.6 \%$ clean floor area, for the $\mathrm{E}$ and the $\mathrm{B}$ method respectively; $P>0.05$ ).

Health records and post-slaughter measurements Health records showed rectal prolapses to be the main reason for taking pigs off trial (seven animals, $3.3 \%$ ). Ten out of the 11 pigs removed came from unstrawed pens (either $N$ or $F$ ). There was no effect of treatments on the incidence of heart abnormalities or parakeratosis of the pars oesophagus of the stomach.

\section{Discussion}

It was concluded that straw provision may provide welfare benefits in terms of pen cleanliness and its properties as a foraging substrate. However, the results of the space allowance treatments suggest that there is no difference in level of welfare offered to finishing pigs between a system which increases space allowance according to the equation suggested by Edwards et al. (1988) and the banded system described in the Welfare Regulations.

The initial publication of the above results (Spoolder et al., 1997) was followed by MAFF's Guidelines on Schedule 3 of the Welfare of Livestock Regulations. The Guidelines reinforce the 1994 Regulations but in addition suggest a 'line $A^{\prime}$ (very similar to the Edwards et al. (1988) equation). Providing space allowances below this line is a direct infringement of the Regulations. Space allowances between line A and the banded line of the Regulations will be the subject of discussions with the producer, who will have to provide an action plan to improve the situation. The report of the EU Scientific Veterinary Committee (1997) recognizes the findings of the above study in part. Conclusion 33 states 'The necessary space for a pig to lie down in lateral recumbancy can be calculated by the formula $0.047 \times$ weight ${ }^{0.67} \mathrm{~m}^{2}$. When the available space has been 0.03 $\times$ weight $^{0.67} \mathrm{~m}^{2}$ per animal, no negative effects on performance have been detected'. These recommendations may form the basis for future EU welfare legislation.

\section{Acknowledgements}

The authors gratefully acknowledge the support received from MAFF. They would also like to thank Dr Tony Lawrence of the University of Liverpool for providing visual aids for scoring stomach lesions, and Mr Edwin Lunn of Geo. Adams for his expertise and skill in collecting the post-slaughter data. Finally, the work of ADAS Terrington's technical staff is also gratefully acknowledged.

\section{References}

Edwards, S. A., Armsby, A. W. and Spechter, H. H. 1988. Effects of floor area allowance on performance of growing pigs kept on fully slatted floors. Animal Production 46: 453-459.

Great Britain Parliament. 1994. Welfare of livestock regulations. Statutory instrument no. 2126. Her Majesty's Stationery Office, London.

Ministry of Agriculture, Fisheries and Food. 1997. Pig space requirements. Her Majesty's Stationery Office, London.

Scientific Veterinary Committee. 1997. The welfare of intensively kept pigs. DOC XXIV/B3/ScVC/0005/1997, European Commission, Brussels.

Spoolder, H. A. M., Corning, S. and Edwards, S. A. 1997. A comparison of methods of specifying stocking density for welfare and performance of finishing pigs on different floor types. Proceedings of the British Society of Animal Science p. 43. 